\title{
Döndürmeli Kaplama Yöntemi ile Kurkumin Kaplanmış Polikaprolakton Nanolif Yara Örtülerinin Hazırlanması ve in vitro Etkinliğinin İncelenmesi
}

\author{
Didem Şen Karaman ${ }^{1 *}$, Nursu Erdoğan ${ }^{2}$ \\ 1* İzmir Katip Çelebi Üniversitesi, Mühendislik ve Mimarlık Fakültesi, Biyomedikal Mühendisliği Bölümü, İzmir, Türkiye, (ORCID: 0000-0002-2368-9598), \\ didem.sen.karaman@ikcu.edu.tr \\ 2 İzmir Katip Çelebi Üniversitesi, Fen Bilimleri Enstitüsü, Biyomedikal Mühendisliği Anabilim Dalı, İzmir, Türkiye (ORCID: 0000-0003-3814-3480), \\ nursuerdogann@gmail.com
}

(İlk Geliş Tarihi 19 Mayıs 2021 ve Kabul Tarihi 3 Ağustos 2021)

(DOI: 10.31590/ejosat.939464)

\begin{abstract}
ATIF/REFERENCE: Şen Karaman, D. Erdoğan, N., (2021). Döndürmeli Kaplama Yöntemi ile Kurkumin Kaplanmış Polikaprolakton Nanolif Yara Örtülerinin Hazırlanması ve in vitro Etkinliğinin İncelenmesi. Avrupa Bilim ve Teknoloji Dergisi, (25), 715-720.

$\ddot{\mathrm{O} z}$

Nanolifler; sahip olduğu geniş yüzey alanı, mekanik özelliklerinin ve çaplarının ayarlanabilir olması sebebiyle yara örtüsü olarak önemli avantajlar sağlamaktadır. Nanolif yara örtüleri, yaranın enfeksiyondan korunmasına yardım ederken yara iyileşmesi için de uygun ortamı sağlar. Buna ilaveten, nanoliflerin terapötik ajanlarla birleştirilmesi lokal tedavi ve yara iyileşmesinin sistemik dolaşımdan bağımsız olmasını sağlayarak vücutta olabilecek zayıf vasküler perfüzyon gibi yara iyileşmesini etkileyecek durumların önüne geçer. Nanoliflere eklenen terapötik ajanlar enfeksiyonların önlenmesine ve enflamasyonun azaltılmasına da uygun ortam sağlayarak yara iyileşmesini desteklemektedir. Bu sebeple nanoliflerin terapötik bir ilaç ile birleştirilmesi lokal ilaç taşıyıcı sistemlerin sağlanmasında avantajlı ve yara iyileşmesinde umut vaat eden bir yaklaşımdır. Yara iyileşmesine katkıda bulunmak amacı ile nanoliflere terapötik ajanların farklı yöntemlerle entegre edilmesi konusunda çalışmalar bulunmaktadır. Fakat nanolif üretiminde en yaygın yöntem olan elektoeğirme, ilacın polimer solüsyonları ile karıştırılarak üretilmesine olanak sağlarken ilaç salım profillerinin yara iyileşme sürecini desteklemesini kısıtlamaktadır. Bu yüzden terapötik ajanların nanolifler ile birleştirilmesinde yenilikçi yaklaşımlar geliştirilmesi gereklidir. Nanoliflere ilaç yüklenme stratejisi olarak döndürmeli kaplamanın bu alanda avantaj sağlayacağı düşünülmektedir. Özellikle nanolifleri oluşturan polimerin degradasyonuna bağlı kalmadan ilaç salımı yapabilecek nanolif yara örtüsünün hazırlanmasına ve literatürde yer alan nanolif -terapötik ilaç birleştirilmesine yenilikçi bir yaklaşım getirilmesine ihtiyaç vardır. Bu çalışmada yara örtüsü olarak oldukça etkin olan nanoliflere ilaç entegre edilmesinde yenilikçi bir yöntem olan döndürmeli kaplama kullanılarak ilaç entegrasyonunun verimliği ve yara örtüsünün özellikleri değerlendirilmiştir. Elde edilen sonuçlar terapötik ajan olarak seçilen kurkuminin döndürmeli kaplama tekniği ile nanoliflere başarılı bir şekilde entegre edildiğini göstermiş ve kurkumin salım profillerinde, kaplanan ilaç miktarının \% $\% 50$ sinden fazlasının ilk iki saat içerisinde salındığı gözlemlenmiştir. Buna ilaveten yalın nanoliflerle karşılaştırıldığında ilaç yüklü nanoliflerin 24 saat sonunda fibroblast hücre çoğalmasını indüklediği gözlemlenmiştir. Bütün olarak değerlendirildiğinde, kurkumin birikimli nanoliflerin hücre çoğalmasında destekleyici olmasının bağ doku yenilenmesi için de faydalı olabileceği ön görülmektedir.
\end{abstract}

Anahtar Kelimeler: Elektroeğirme, Nanolif, Yara örtüsü, Döndürmeli kaplama, Kurkumin.

\section{Preparation of Curcumin Spin-coated Polycaprolactone Nanofiber Wound Dresses and Investigation of in vitro Efficacy}

\begin{abstract}
The high surface area, tunable mechanical properties of nanofibers are beneficial as wound dressings. Nanofiber wound dressings provide an appropriate environment for wound healing while employing protection against infections. Moreover, integration of nanofibers and therapeutics agents can be employed as local treatment and to ensure an independent healing process thereby restrain conditions such as poor vascular perfusion that affect wound healing. Integration of therapeutic agents into nanofibers supports wound healing by providing a convenient environment for inhibition of infections and reducing inflammation. For that reason, the integration of therapeutics agents to nanofibers is advantageous to provide local drug delivery and a promising approach for wound healing. In literature, there are many studies about the integration of therapeutics agents to nanofibers employed with various methods to enhance wound healing. Electrospinning is a common technique for producing nanofiber and allows nanofiber fabrication by blending polymer solutions and drug however blending of drug and polymer solutions limit the demanded drug release for wound healing. It is direly needed to develop an approach for the integration of and therapeutic agents to nanofibers wound dressing whereas drug release is independent of polymer degradation. Therefore, innovative approaches needed to be employed for the integration of nanofibers and
\end{abstract}

*Sorumlu Yazar: didem.sen.karaman@ikcu.edu.tr 
therapeutic agents. In this study, the spin coating was employed for the accommodation of, the therapeutics content, curcumin on the nanofibers followed by the investigation of the efficiency of the spin-coating approach for the drug integration on nanofibers to be employed as a wound dressing. The results showed that accommodation of curcumin onto nanofibers was performed successfully by spin-coating and more than $50 \%$ of accommodated curcumin was released in 2 hours. Furthermore, drug-loaded nanofibers improved fibroblast cell proliferation for $24 \mathrm{~h}$ in comparison to pristine nanofiber. In view of all, curcumin deposited nanofibers are considered as profitable for connective tissue regeneration by means of supporting cell proliferation.

Keywords: Electrospinning, Nanofibers, Wound dressing, Spin coating, Curcumin.

\section{Giriş}

Yara iyileşmesi doku yenilenmesinin ve büyümesinin dinamik ve karmaşık bir sürecidir. Bu süreci etkileyen etkenlerden biri de kullanılan yara örtüsü malzemesidir (Dhivya, Padma ve Santhini, 2015). Yara örtüleri yaranın enfeksiyondan korunmasına yardım ederken yara iyileşmesi için de uygun ortamı sağlar. Yara iyileşmesinde sistemik ilaç uygulama yöntemleri günümüzde alışılagelmiş yöntemlerdir. Fakat ilaçların hasarlı bölgede yetersiz miktarda birikmesine böylece de yüksek dozlarda tekrar ilaç uygulamasına sebep olabilir. Ayrıca, sistemik yolla alınan ilaçlar vücutta hızlı bir şekilde bozunmaya uğrayabilir ve boşaltım sistemi ile vücuttan uzaklaştırılabilir (Saka, Sathe ve Khan, 2019). Sistemik ilaç uygulama yöntemlerinin kısıtlamalarının aşılması için ilaçların direkt olarak hasarlı bölgeye uygulanmasına olanak veren lokal uygulama için ilaç iletim sistemlerinin tasarlanmasına ihtiyaç vardır (Wen, Jung ve Li, 2015).Terapötik ajanlarla lokal tedavi, yara iyileşmesinin sistemik dolaşımdan bağımsız olmasını sağlar ve böylece vücutta olabilecek zayıf vasküler perfüzyon gibi yara iyileşmesini etkileyecek durumlara karşı nanoliflerin enfeksiyonu ve enflamasyonu azaltması, uygun ortam sağlayarak yara iyileşmesini desteklemesi beklenmektedir (Chen ve diğerleri, 2017). Nanoliflerin terapötik bir ilaç ile birleştirilmesiyle yapılacak lokal ilaç taşıyıcı sistemin yara iyileşmesi yerine kullanılması umut vaat eden bir yaklaşımdır. Özellikle inflamasyonun azaltılması amaciyla antiflamasyon ilaçların lokal olarak bölgeye uygulanmasının gerekebileceği düşünülmektedir. $\mathrm{Bu}$ yüzden, literatürde yara iyileşmesini arttırmak için farklı polimerlerden üretilmiş nanoliflere terapötik ajanların entegre edildiği birçok çalışma bulunmaktadır (Lee ve diğerleri, 2014; Miguel ve diğerleri, 2018; Shokrollahi, Bahrami, Nazarpak ve Solouk, 2020; Xie ve diğerleri, 2013; M. Yu ve diğerleri, 2020).

Son zamanlarda elektroeğirme yöntemi ile üretilen nanolifler sahip olduğu avantajlar sayesinde yaygın olarak kullanılmaya başlanmıştır. Ucuz bir yöntem olan elektroeğirme ile üretilen nanolifler sahip olduğu geniş yüzey alanı, mekanik özellikleri ve çaplarının ayarlanabilir olması sebebiyle ilaç iletim sistemi olarak kullanılabilir (Turanli ve Acartürk, 2018). Nanoliflerin nanoboyutta ve gözenekli yapıları sayesinde geniş yüzey alanına sahip olmaları biyoaktif yara örtüsü olarak etken maddelerin kontrollü salımında kullanılmaları ve canlı hücre üreyebilmesi için fizyolojik ortamı taklit edebilmeleri açısından ön plana çıkmaktadırlar (Kurtoğlu ve Karataş, 2009). Yapılan çalışmalarda özellikle elektroeğirme yöntemi ile oluşturulan polimerik nanoliflerin yüzey alanlarının oldukça geniş olması, liflerin çaplarının hücre tutunmasına uyumlu olacak şekilde ayarlanabilmesi, yüzey özelliklerinin değiştirilmesiyle mekanik özelliklerinin ayarlanması dura grefti hazırlanması için oldukça avantajlıdır (Mohtaram ve diğerleri, 2015). Buna ek olarak farklı polimerlerin işlevselliğin arttırılması için terapötik ajanlarla birleştirilmesi literatürde kabul görmüş bir strateji olarak yer almaktadır (Patel ve Yadav, 2018). Biyobozunur ve biyouyumlu bir polyester olan, Amerika Birleşik Devletleri Gıda ve İlaç
Kurumu (FDA) onaylı polikaprolakton (PCL) kullanılarak elde edilen elektroeğrilmiş nanolifler, gözenekli yapıya sahip elastik morfoloji sayesinde gaz değişimine olanak sağlamakta ve yara bölgesindeki eksudat için rezarvuarlar sağlamaktadır. Ancak, PCL in yara bölgesine kuvvetli şekilde tutunma eğilimi göstermesi tamir olan yeni deri dokusunun zarar görmesine ve tedavi sürecinin uzamasına neden olmaktadır (İşoğlu, 2019). Bu da üstün mekanik özelliklere sahip PCL' nin tek başına yara örtüsü olarak kullanımını sınırlamaktadır.

Yara tedavilerinde sistemik uygulama yolları ile verilen bazı ilaçların (örneğin kurkumin) biyoyararlanımı düşüktür. Kurkuminin; antioksidan, antikanserojenik, antimutajenik, antidiyabetik, antibakteriyel, antiviral, antiinflamatuar, antinosiseptif etkileri ile geniş bir biyolojik ve farmakolojik etkiye sahip olduğu literatürde sunulmuştur. Fakat bu çalışmada kullanılan ve yara iyileştirme etkinliği bilinen kurkuminin ağızdan verildiğinde yüksek kararlılıkta çözünmesi azdır. Kurkumin değerlendirildiğinde ilacın hidrofobik yapısından dolayı ilaçların istenen biyoyararlanımı göstermesi için etkin ilaç taşıyıcı sisteme ihtiyaç doğmaktadır. Yapılan araştırmalar, nanoliflerin, bu tip ilaçları taşımada uygun taşıyıcılar olduğu ağızdan alınana göre iyileştirme etkisinin arttığı doğrultusundadır (Merrell ve diğerleri, 2009). Örneğin, hidrofobik yapısı yüzünden düşük biyoyararlanıma ve uyumluluğa sahip kurkuminin nanolifler ile biyouyumluluğu ve kararlılı̆̆ı arttırılabilir. Böylece antiinflamasyon, antioksidant ve yara iyileşmesi özelliklerinden daha etkin yararlanılabilir (Fereydouni ve diğerleri, 2018).

Bu çalışmada yenilikçi bir yaklaşımla; çoğunlukla uygulanan elektroeğirme yapılacak polimerin içine uygulama öncesi ilaç katkılandırma yönteminden farklı olarak döndürmeli kaplama tekniği ile PCL nanoliflere kurkumin birikimi yapılarak yara örtüsü olarak uygulanabilecek lokal ilaç iletim sistemi tasarlanmıştır. $\mathrm{Bu}$ sayede kurkumin salımının nanoliflerin degridasyonuna bağlı kalmaksızın lokal olarak istenilen bölgede etkinlik göstermesi sağlanabilecektir. Bunun yanı sıra elde edilen kurkumin kaplı PCL nanoliflerin doku yenilenmesi için in vitro ortamda fibroblast hücre canlılığına olan etkisinin incelenmiştir.

\section{Materyal ve Metot}

\subsection{Nanoliflerin Üretimi ve Karakterizasyonları}

Nanolif üretimi için PCL polimeri (\%10 a/h)(Sigma Aldrich; ortalama Mn 80,000) 3:1 hacimsel oranında kloroform (Merck Millipore) ve dimetilformamid (Isolab) karışımı içerisinde çözdürülmüştür. Elde edilen polimer karışımı ile elektroeğirme cihazında $20 \mathrm{kV}$ elektrik potansiyel, $20 \mathrm{~cm}$ şırınga ucu-toplaç uzaklığı ve $1 \mathrm{~mL} / \mathrm{sa}$ pompalama hızı kullanılarak nanolifler oluşturulmuştur (Zhang ve diğerleri, 2011). Üretilen nanolifler vakum altında saklanmıştır.

\subsubsection{Nanoliflerin Morfolojik Özelliklerinin İncelenmesi}

Üretilen nanoliflerin morfolojik yapıları taramalı elektron mikroskobu (SEM; Carl Zeiss, Almanya) ile incelenmiştir. İlk olarak, fiberler vakumlanarak nem uzaklaştırılmış ve 60 saniye 
boyunca altın ile kaplanmıştır (Quorum Q150 RES, Birleşik Krallık). Nanoliflerin çap dağılımı Image J 1.52a yazılımı ile belirlenmiştir.

\subsubsection{Islanabilirlik Testi}

Nanoliflerin yüzey ıslanabilirliği, yüzey temas açısı ölçümü Attension Theta Lite Optical Tensiometer (Biolin Scientific, İsveç) ve Image J 1.52a yazılımı ile belirlenmiştir. Sonuçlar istatistiksel olarak GraphPad Prism 8.4.2 ordinary one-way ANOVA-Sidak's çoklu karşılaştırma testi ile değerlendirilmiştir.

\subsubsection{Su Tutma Kapasitesinin Belirlenmesi}

Üretilen nanoliflerin su tutma kapasitelerinin belirlenmesi için örnekler fosfat tampon çözeltisi içerisinde (pH: 7.2, $10 \mathrm{mM})$ 24 saat boyunca bekletilmiştir. Ertesi gün nanoliflerin ilk ağırlıklarına göre ortalama ağırlık artışları bulunarak su tutma yüzdeleri hesaplanmıştır. Sonuçlar istatistiksel olarak GraphPad Prism 8.4.2- 2way ANOVA-Sidak's çoklu karşılaştırma testi ile değerlendirilmiştir.

\subsubsection{Nanoliflerin Biyobozunumunun İncelenmesi}

Nanoliflerin biyobozunumunun incelenmesi için distile su içerisinde $124 \mathrm{mM} \mathrm{NaCl}, 2 \mathrm{mM} \mathrm{KCl}, 2 \mathrm{mM} \mathrm{MgSO} 4,1.25 \mathrm{mM}$ $\mathrm{NaH}_{2} \mathrm{PO}_{4}, 2 \mathrm{mM} \mathrm{CaCl}, 26 \mathrm{mM} \mathrm{NaHCO} 3,10 \mathrm{mM}$ D-glukoz çözdürülerek yapay vücut sıvısı (pH: 7.4) hazırlanmıştır (Moyer ve Brown, 1998). Daha sonra örnekler yapay vücut sıvısı içerisine daldırılmış ve $37^{\circ} \mathrm{C}$ 'de çalkalayıcıda bırakılmıştır. İlk ağırlıklarına göre fiberlerin ağırlık kaybı 1., 2., 7., 14. ve 28. günlerde hesaplanmıştır. Sonuçlar istatistiksel olarak GraphPad Prism 8.4.2 2way ANOVA-Tukey's çoklu karşılaştırma testi ile değerlendirilmiştir.

\subsection{Nanolif Yüzeylerinin Kurkumin ile Kaplanması ve Karakterizasyonu}

Nanoliflerin kurkumin ile kaplanması için döndürmeli kaplama tekniği (Laurell Spin Coater; model WS-400BZ6NPP/LITE) kullanılmıştır. İlk olarak nanolifler biyouyumlu silikon ile yuvarlak cam lameller üzerine yapıştırılarak sabitlenmiştir. Kurkumin (Sigma Aldrich) $1 \mathrm{mg} / \mathrm{mL}$ konsantrasyonunda (4-(2-hidroksietil)-1-piperazineetansulfonik asit) (HEPES; Sigma Aldrich) içerisinde sonikasyon cihazı yardımıyla dağıtılmıştır. Daha sonra lif yüzeyleri $\% 0.1(\mathrm{a} / \mathrm{h})$ sürfaktan içeren HEPES ile sslatılmış ve hazırlanan kurkumin solüsyonunundan lif yüzeylerine $20 \mu \mathrm{g}, 50 \mu \mathrm{g}$ ve $100 \mu \mathrm{g}$ kurkumin içeren hacimlerde damlatılmıştır. Kurkuminin lif üzerinde birikimi için döndürmeli kaplama 5 saniye boyunca 500 rpm daha sonra 4000 rpm hızında 1 dakika boyunca uygulanmıştır (Wang ve diğerleri, 2016). Örnekler $30^{\circ} \mathrm{C}$ 'de bir gün boyunca etüvde kurutulmuştur. Kurkumin kaplanan liflerin morfolojik yapısı SEM ile incelenmiştir. Ayrıca, kurkumin kaplama yapılmış nanoliflerin çap dağılımları ve temas açıları Image J 1.52a yazılımı ile belirlenmiştir.

\subsection{Nanolif Yüzeylerindeki Kurkumin Miktarının Tayin Edilmesi}

Kurkumin miktarının belirlenmesi için ilk olarak standart eğrisi oluşturulmuştur. Detayında; PCL nanolifi konsantrasyonu $1 \mathrm{mg} / \mathrm{mL}$ olacak şekilde kloroformda çözdürülmüş ve içerisine 2.5 $\mu \mathrm{g} / \mathrm{mL}, 5 \mu \mathrm{g} / \mathrm{mL}, 10 \mu \mathrm{g} / \mathrm{mL}, 20 \mu \mathrm{g} / \mathrm{mL}$ konsantrasyonlarında kurkumin eklenmiştir. Hazırlanan solüsyonlar spektrofotometrik olarak ölçülmüş ve $420 \mathrm{~nm}$ 'de standart eğri oluşturulmuştur. Farklı başlangıç miktarlarında üzerine $(20 \mu \mathrm{g}, 50 \mu \mathrm{g}$ ve $100 \mu \mathrm{g})$ e-ISSN: 2148-2683
Nanoliflerin yüzey temas açısı ölçümü Attension Theta Lite Optical Tensiometer (Biolin Scientific, İsveç) ve Image J 1.52a yazılımı ile belirlenmiştir. Sonuçlar istatistiksel olarak GraphPad Prism 8.4.2 ordinary one-way ANOVA-Sidak's çoklu karşılaştırma testi ile değerlendirilmiştir.

döndürmeli kaplama ile kurkumin biriktirilen örneklere, nanoliflerin konsantrasyonları $1 \mathrm{mg} / \mathrm{mL}$ olacak hacimde kloroform eklenmiş ve çözdürülmüştür. Elde edilen kurkumin ve PCL içeren solüsyon ultraviyole ve görünür 1şık spektrofotometre ile okunmuştur. Ölçülen absorbans değerleri oluşturulan standart eğrisi ile fiber üzerindeki kurkumin miktarının hesaplanmasında kullanılmıştır (Rüzgar ve diğerleri 2013; Yu ve diğerleri, 2010).

\subsection{Kurkumin ile Kaplı Nanoliflerden İlaç Salımının İncelenmesi}

İlaç salımının incelenmesi \%1 lik tween 80 sürfaktan içeren pH'1 7.4 olan fosfat tampon çözeltisi hazırlanarak sink koşullarına benzer koşullar oluşturularak 0.5, 1., 2., 4., 6., 8., 12., 24., 48., 56. saatlerde spektroskopik analiz yöntemler ile gözlemlenmiştir (Sadri, Mohammadi ve Hosseini, 2016). Spektroskopi ölçümlerinden sonra analiz sonuçları ile zamana karşı kümülatif ilaç salım grafiği çizilerek kurkumin kaplanmış nanoliflerden gerçekleşen ilaç salım profili tayin edilmiştir. İlaç salım analizine başlamadan önce fiberlerdeki kurkuminin kaplama oranı dikkate alınarak salım profili belirlenmiş̧tir.

\subsection{Kurkumin Kaplı Nanoliflerin in vitro Sitotoksisitesi}

Kurkumin kaplanan nanoliflerin canlılık testi için L929 fare fibroblast hücre hattı kullanılmıştır. Hücreler \%10 fetal sığır serumu ve \%1 penisilin-streptomisin içeren besiyeri (DMEM; Dulbecco's Modified Eagle Medium) kullanılarak çoğaltılmış ve besiyerleri 2 günde bir taze besiyeri ile değiştirilmiştir. Yeterli yoğunluğa ulaşan hücreler standart hücre kültürü şişeleri yüzeylerinden kaldırılmış ve 24 kuyucuklu plakalara $5 \times 10^{4}$ hücre/kuyu yoğunluğunda ekilmiştir. Hücrelerin tutunmaları için plakalar 16-18 saat $37{ }^{\circ} \mathrm{C}^{\prime} \mathrm{de} \% 5 \quad \mathrm{CO}_{2}$ içeren inkübatorde bırakılmıştır. Kurkumin birikimi yapılan nanolif örnekleri sterilizasyon için 1 saat boyunca ultraviole 1 şı ğı altında bekletilmiştir. ISO 10993-5:2009(E) 'de yer alan direkt temas testine göre kurkumin birikimi yapılan nanolifler 24 kuyucuklu plakalara ekilen hücreler üzerine dikkatli bir şekilde yerleştirilmiştir. Kontrol grubu olarak sadece yuvarlak cam lameller kullanılmıştır. Nanolifler ile muamele edilen hücrelerin canlılı̆̆ 72 saat boyunca 3-(4,5-dimetiltiyazol2-yl)-2,5difeniltetrazolyum-bromür (MTT) testi ile belirlenmiş, absorbans değerleri canlılık ile ilişkilendirilmiştir.

\section{Araştırma Sonuçları ve Tartışma}

\subsection{Nanoliflerin Fizikokimyasal Karakterizasyonları}

Üretilen PCL nanoliflerinin kaplama öncesi ve sonrası çap dağılımı Image J 1.52a yazılımı ile bulunmuş; Şekil 1'de histogram grafikleri verilmiştir. Sonuçlara göre, 201-300 nm aralığında çap uzunluğuna sahip nanolifler üretilmiştir ve kurkumin kaplama nanoliflerin çap uzunlukları üzerinde bir değişikliğe yol açmamıştır. Ayrıca, nanoliflerin morfolojik özellikleri taramalı elektron mikroskobu ve 1ş1k mikroskobu ile incelenmiştir. Şekil 2'de kaplamasız ve farklı miktarlarda kurkumin kaplama yapılan nanolifler rastgele hizalanmış ve 
birbirlerine bağlı porlu yapılar oluşturmuştur. Kaplama yapılan nanolifler üzerinde kurkumin birikiminin gerçekleştiği ve kaplamanın nanolif morfolojisini etkilemediği gözlemlenmiştir.

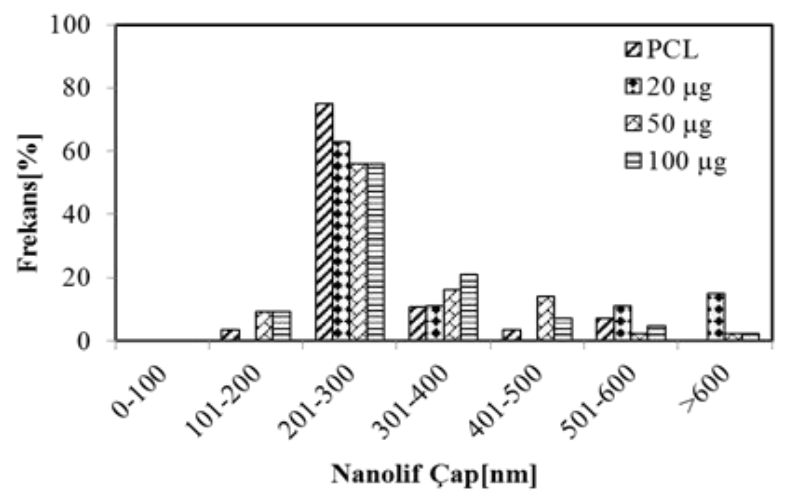

Şekil 1. Kaplama Öncesi ve Sonrası Nanoliflerin Çap Dă̆ılımı

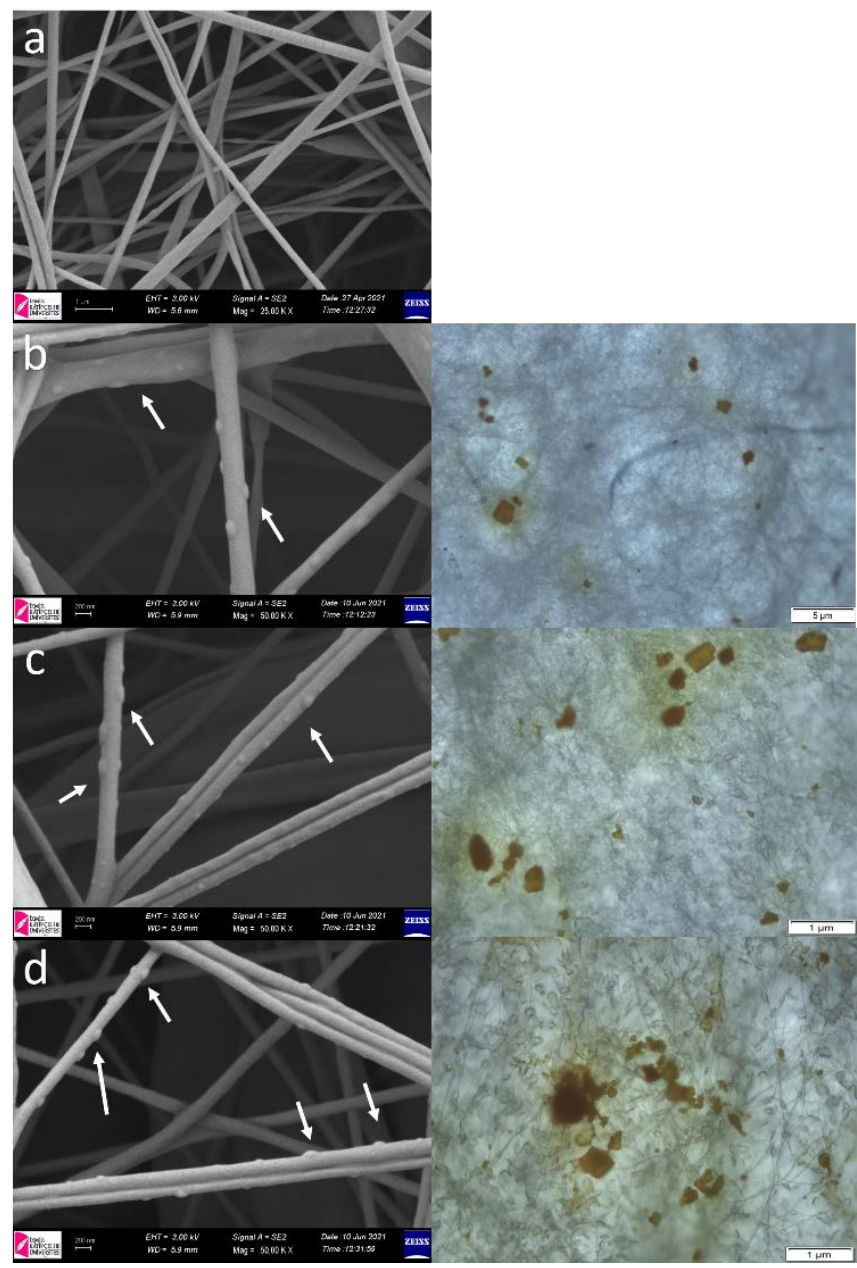

Şekil 2. Kaplama Öncesi ve Sonrası Nanoliflerin Mikroskop

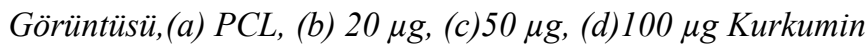
Kaplanmış Nanolifler

Nanolifler kaplama öncesi ve sonrası 1slanabilirlik açısından yüzey temas açısı testi ile değerlendirilmiştir (Şekil 3). Teste göre kaplama öncesi PCL nanolif yüzeyinin su damlası ile arasındaki açı $121.4^{\circ} \pm 0,3$ olarak ölçülmüştür. 20,50 ve $100 \mu \mathrm{g}$ kurkumin kaplama sonrası nanoliflerin yüzey teması açıları sırasıyla $116.8^{\circ} \pm 1.5, \quad 115.5^{\circ} \pm 2, \quad 124.2^{\circ} \pm 3.2$ bulunmuştur. Analizler sonrasında $20 \mu \mathrm{g}$ ve $50 \mu \mathrm{g}$ kurkumin kaplanan nanoliflerin yüzey temas açıları ile $100 \mu \mathrm{g}$ kurkumin kaplanan nanolifin temas açısı arasında istatiksel olarak anlamlı fark oluştrulduğu $\quad(p<0.05)$ bulunmuştur. $\mathrm{Bu}$ durum kaplanan kurkumin miktarındaki artışa bağlı olarak yüzeylerinde daha çok kurkumin birikimi olmasıyla ilişkilendirilmiştir. Sonuca göre tüm nanoliflerin hidrofobik özelliğe sahip olduğu gösterilse de en az miktardaki 20 ug kurkumin miktarının en düşük temas açısına sebebiyet verdiği gözlemlenmiştir. Literatürde yer alan PCL liflerin temas açıları değerlendirildiğinde özellikle PCL nanoliflerin çaplarının temas açısı üzerinde etkisi olduğu gösterilmiştir (Oliveira, Mattoso, Orts ve Medeiros, 2013). Buna ilaveten alifatik özellikteki PCL ve PLLA gibi polimerlerden elde edilen nanoliflerin genellikle 116$135^{\circ}$ arasında temas açısına sahip olduğu ifade edilmiştir (Niemczyk-Soczynska, Gradys ve Sajkiewicz, 2020).

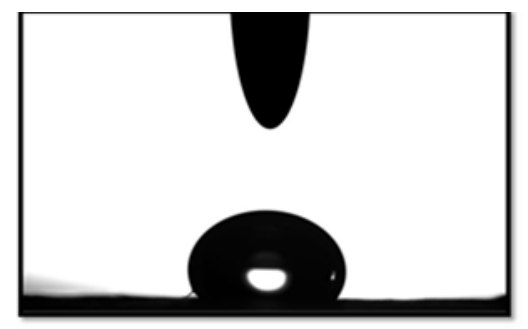

\section{Şekil 3. PCL Nanoliflerinin Yüzey Islanabilirlik Testi}

Yüzeyine kurkumin birikimi gerçekleştirilen nanoliflerin su tutma kapasiteleri Şekil 4'teki grafikte gösterilmiştir. Farklı başlangıç miktarlarındaki kurkumin birikiminin nanoliflerin su tutma kapasitelerinde anlamlı bir fark oluşturmadığı görülmüştür. Buna karşın kurkumin kaplaması yapılmamış yara örtüsü ile karşılaştırıldığında su tutma kapasitesinin arttığı gözlemlenmiştir. Buna benzer bir durum yara örtüsünün yüzeyinde bulunan kurkuminin kimyasal yapısındaki oksijenin proton donor özelliğinden dolayı su ile bağlanmayı arttırması olarak literatürde tartışılmıştır (Ranjbar-Mohammadi ve Bahrami, 2016).

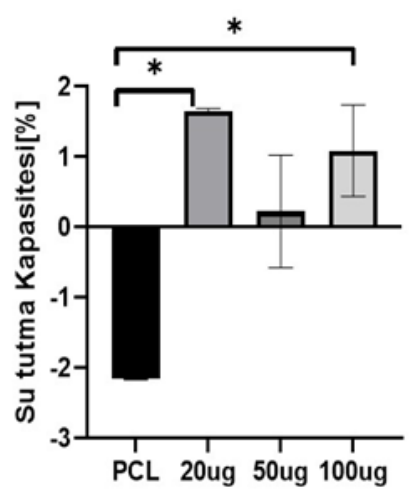

Şekil 4. Nanoliflerin Su Tutma Kapasitesi Tayini. Grafik Ortalama ve Standart Sapma Değerlerini Göstermektedir. * $\dot{I}_{\text {şareti } p}<0.05$ 'i Ifade Etmektedir.

PCL nanoliflerin bozunma miktarı, simüle edilmiş vücut sıvısı içerisinde 28 gün boyunca takip edilmiştir (Şekil 5). PCL nanolifleri 28 gün sonunda bozunma göstermemiştir. Sonuç olarak PCL nanolifler ile uzun sürede tekrar emilebilir matlar üretilebileceği belirtilmiştir. 


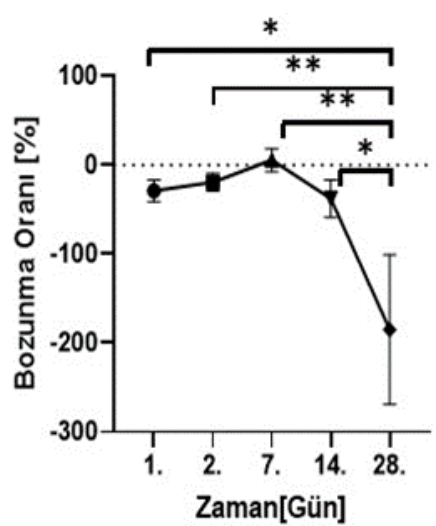

Şekil 5. PCL Nanolifinin Bozunma Orant. Grafik Ortalama ve Standart Sapma Değerlerini Göstermektedir. * Işareti $p<0.05$ 'i , ** Işsareti $p<0.01$ 'i Iffade Etmektedir.

\subsection{Nanolif Yüzeylerinin Kurkumin Miktarları ve Kurkumin Salım Profili}

Kurkumin birikimi yapılan nanoliflerin kurkumin biriken miktarları uygulanan yöntemle $20 \mu \mathrm{g}, 50 \mu \mathrm{g}$ ve $100 \mu \mathrm{g}$ sirası ile $0.1 \pm 0.01(\mathrm{a} / \mathrm{a} \%), 0.2 \pm 0.01(\mathrm{a} / \mathrm{a} \%)$ ve $0.5 \pm 0.01(\mathrm{a} / \mathrm{a} \%)$ olan miktarlarda sağlanmıştır. Kurkumin salım profillerinden elde edilen sonuçlar Şekil 6'da verilmiştir. Elde edilen sonuçlarda beklenildiği yönde artan kurkumin birikimi ile ilk 2 saat içerisinde elde edilen salım miktarı da artmaktadır. Sırası ile en düşük birikim miktarında sahip olan nanolifin üzerindeki kurkuminin $\% 65$ 'i , orta seviyede $(0.2 \pm 0.01$ (a/a \%) birikim miktarına sahip olan nanolifin üzerindeki kurkuminin \%69' u ve en yüksek birikim miktarında sahip olan nanolifin üzerindeki kurkuminin \%95'ı ilk iki saatte salınmıştır. Elde edilen kurkumin salım profili değerlendirildiğinde eş parametreler ile farklı dozlarda çalışılarak ilaç çözünürlüğünde olumlu yönde değişiklik elde edilebileceğinin göstergesi olarak kabul edilebilir. Bunun yanı sıra literatürde gerçekleştirilen çalışmalar incelendiğinde döndürmeli kaplama yöntemi sayesinde gelişmiş ilaç salımı ile kuru koşulların sağlandığı kararlı amorf yapıda ilaç biriktirilmesinin sağlanabildiği gösterilmiştir(Albarahmieh, Albarahmieh ve Alkhalidi, 2018).

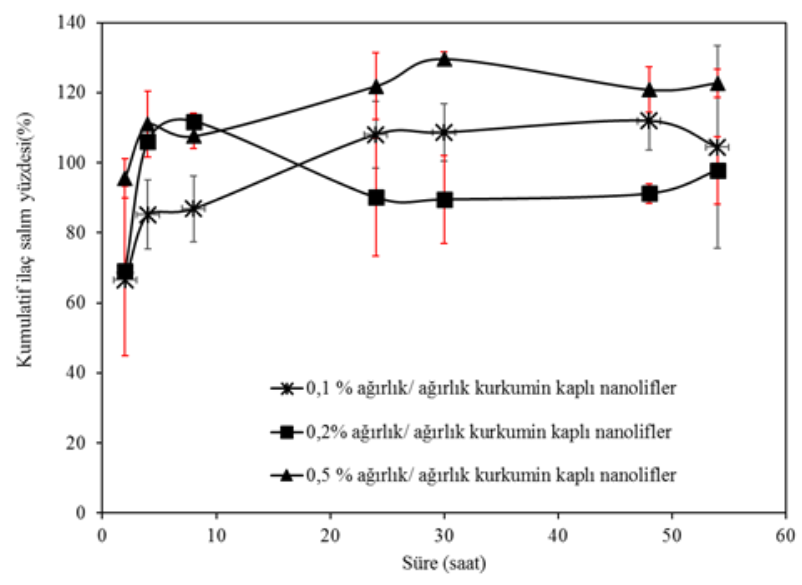

Şekil 6. Zamana Bağlı Kümülatif Kurkumin Salım Profili

Sitotoksisite testi için hücre canlılıkları 3 gün boyunca incelenmiştir. Şekil 7'de gösterildiği üzere ilk 24 saat kurkumin birikimli nanolifler ile muamele edilmiş hücrelerin canlılıkları kontrol grubuna göre artış göstermiştir. 48. ve 72. saat sonunda e-ISSN: 2148-2683 hücre canlılıkları 24.saat sonuçlarına göre azalma göstermiş fakat hücre canlılığını toksik düzeyde etkilenmemiştir.

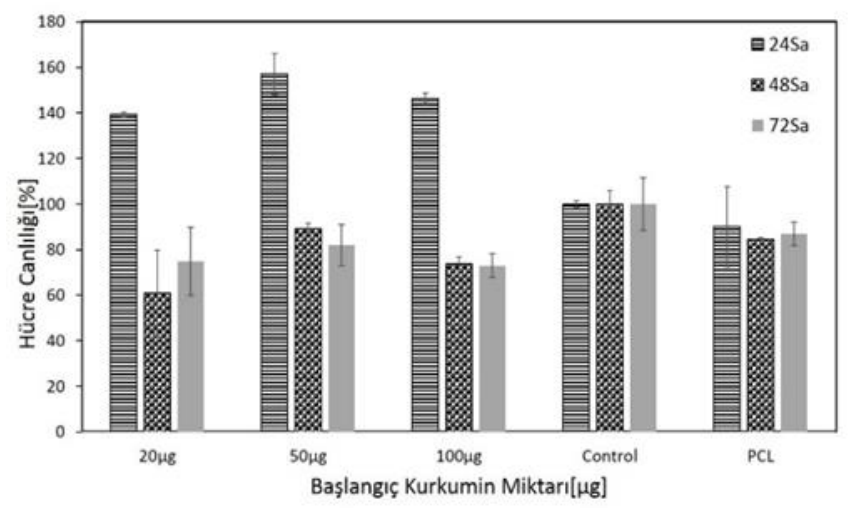

Şekil 7. Hücre Canlılık Sonuçları

\section{Değerlendirmeler}

Elde edilen veriler özellikle döndürmeli kaplama tekniğinin nanolifler üzerine en kısa sürede lokal olarak en etkin ilaç iletiminin sağlanması için uygulanabilir bir yöntem olduğunu göstermiştir. $\mathrm{Bu}$ sayede özellikle nanoliflerin bozunmasına ihtiyaç duyulmadan ilk 2-4 saat içerisinde ilaç salımının sağlanabileceği gösterilmiştir. Buna ilaveten ilk 24 saatte elde edilen yüksek ilaç salım miktarının doku-yara örtüsü etkileşimini olumlu yönde etkilediği gözlemlenmiştir. Bu bağlamda ilerleyen çalışmalarda farklı kompozisyonlardaki nanolif blendlerinin döndürmeli kaplama tekniği ile birleştirildiğinde ilaç salım profilini etkileyip etkilemediği konusunda çalışmaların gerçekleştirilmesi planlanmaktadır. Gerçekleştirilen çalışmada döndürmeli kaplama ile ilaç birikimi lokal ilaç iletimi konusunda başarılı bir şekilde gösterilmiştir.

\section{Teşekkür}

Bu çalışma İzmir Katip Çelebi Üniversitesi, Bilimsel Projeler Koordinatörlüğü (BAP) tarafından 2019-TYL-FEBE-0010 nolu proje ile desteklenmiştir. Ayrıca, çalışmada döndürmeli kaplama cihazının kullanımındaki yardımlarından dolayı İzmir Katip Çelebi Üniversitesi-Organik Yarı İletken Malzemeler Uygulama Laboratuvarına ve L929 fibroblast hücre hattının temin edilmesine yardımcı olan Dr. Öğr. Üyesi Gülşah Erel Akbaba ‘ya teşekkür ederiz.

\section{Kaynakça}

Albarahmieh, E., Albarahmieh, M. ve Alkhalidi, B. A. (2018). Fabrication of Hierarchical Polymeric Thin Films by Spin Coating Toward Production of Amorphous Solid Dispersion for Buccal Drug Delivery System: Preparation, Characterization, and In Vitro Release Investigations. Journal of Pharmaceutical Sciences, 107(12), 3112-3122. doi:10.1016/j.xphs.2018.08.019

Chen, S., Liu, B., Carlson, M. A., Gombart, A. F., Reilly, D. A. ve Xie, J. (2017). Recent advances in electrospun nanofibers for wound healing. Nanomedicine, 12(11), 1335-1352. doi:10.2217/nnm-2017-0017 
Dhivya, S., Padma, V. V. ve Santhini, E. (2015). Wound dressings - a review. BioMedicine, 5(4), 22. doi:10.7603/s40681-0150022-9

Fereydouni, N., Darroudi, M., Movaffagh, J., Shahroodi, A., Butler, A. E., Ganjali, S. ve Sahebkar, A. (2018). Curcumin nanofibers for the purpose of wound healing. Journal of Cellular Physiology, jcp.27362. doi:10.1002/jcp.27362

İşoğlu, İ. A. (2019). Yara Örtü Malzemesi Olarak Elektroeğrilmiş PCL/PHBV Membranların Hazırlanması ve Karakterizasyonu. Bitlis Eren Üniversitesi Fen Bilimleri Dergisi, 8(3), 1029-1044. doi:10.17798/bitlisfen.530767

Kurtoğlu, A. H. ve Karataş, A. (2009). Yara tedavisinde güncel yaklaşımlar: Modern yara örtüleri. Ankara Üniversitesi Eczacılık Fakültesi Dergisi, 38(3), 211-232. doi:10.1501/Eczfak_0000000562

Lee, C.-H., Hsieh, M.-J., Chang, S.-H., Lin, Y.-H., Liu, S.-J., Lin, T.-Y., Juang, J.-H. (2014). Enhancement of Diabetic Wound Repair Using Biodegradable Nanofibrous Metformin-Eluting Membranes: In Vitro and in Vivo. ACS Appl. Mater. Interfaces, $\quad 6(6), \quad 3979-3986$. doi:dx.doi.org/10.1021/am405329g

Merrell, J. G., McLaughlin, S. W., Tie, L., Laurencin, C. T., Chen, A. F. ve Nair, L. S. (2009). Curcumin-loaded poly( $\varepsilon-$ caprolactone) nanofibres: Diabetic wound dressing with antioxidant and anti-inflammatory properties. Clinical and Experimental Pharmacology and Physiology, 36(12), 11491156. doi:10.1111/j.1440-1681.2009.05216.x

Miguel, S. P., Figueira, D. R., Simões, D., Ribeiro, M. P., Coutinho, P., Ferreira, P. ve Correia, I. J. (2018). Electrospun polymeric nanofibres as wound dressings: A review. Colloids and Surfaces B: Biointerfaces, 169, 60-71. doi:10.1016/j.colsurfb.2018.05.011

Mohtaram, N. K., Ko, J., Agbay, A., Rattray, D., Neill, P. O., Rajwani, A., Willerth, S. M. (2015). Development of a glial cell-derived neurotrophic factor-releasing artificial dura for neural tissue engineering applications. Journal of Materials Chemistry B, 3(40), 7974-7985. doi:10.1039/C5TB00871A

Moyer, J. R. ve Brown, T. H. (1998). Methods for whole-cell recording from visually preselected neurons of perirhinal cortex in brain slices from young and aging rats. Journal of Neuroscience Methods, 86(1), 35-54. doi:10.1016/S01650270(98)00143-5

Niemczyk-Soczynska, B., Gradys, A. ve Sajkiewicz, P. (2020). Hydrophilic Surface Functionalization of Electrospun Nanofibrous Scaffolds in Tissue Engineering. Polymers, 12(11), 2636. doi:10.3390/polym12112636

Oliveira, J. E., Mattoso, L. H. C., Orts, W. J. ve Medeiros, E. S. (2013). Structural and Morphological Characterization of Micro and Nanofibers Produced by Electrospinning and Solution Blow Spinning: A Comparative Study. Advances in Materials Science and Engineering, 2013, 1-14. doi:10.1155/2013/409572

Patel, G. C. ve Yadav, B. K. (2018). Polymeric nanofibers for controlled drug delivery applications. Organic Materials as Smart Nanocarriers for Drug Delivery içinde (ss. 147-175). Elsevier. doi:10.1016/B978-0-12-813663-8.00004-X
Ranjbar-Mohammadi, M. ve Bahrami, S. H. (2016). Electrospun curcumin loaded poly( $\varepsilon$-caprolactone)/gum tragacanth nanofibers for biomedical application. International Journal of Biological Macromolecules, 84, 448-456. doi:10.1016/j.ijbiomac.2015.12.024

Rüzgar, G., Birer, M., Tort, S. ve Acartürk, F. (2013). Studies on Improvement of Water-Solubility of Curcumin With Electrospun Nanofibers. FABAD J. Pharm. Sci 38(3), 143149.

Sadri, M., Mohammadi, A. ve Hosseini, H. (2016). Drug release rate and kinetic investigation of composite polymeric nanofibers. Nanomed Res J, 1(2), 112-121. doi:10.7508/nmrj.2016.02.008

Saka, R., Sathe, P. ve Khan, W. (2019). Brain local delivery strategy. H. Gao ve X. Gao (Ed.), Brain Targeted Drug Delivery System:A Focus on Nanotechnology and Nanoparticulates içinde (ss. 241-286). Elsevier. doi:10.1016/B978-0-12-814001-7.00011-1

Shokrollahi, M., Bahrami, S. H., Nazarpak, M. H. ve Solouk, A. (2020). Multilayer nanofibrous patch comprising chamomile loaded carboxyethyl chitosan/poly(vinyl alcohol) and polycaprolactone as a potential wound dressing. International Journal of Biological Macromolecules, 147, 547-559. doi:10.1016/j.ijbiomac.2020.01.067

Turanli, Y. ve Acartürk, F. (2018). Nanofibers and Applications as Colon Specific Drug Delivery System. Journal of Literature Pharmacy Sciences, 7(1), 11-23. doi:10.5336/pharmsci.201756338

Wang, Q., Ye, L., Wang, L., Li, P., Cao, Y. ve Li, Y. (2016). Rapid nanopatterning technique based on monolayer silica nanosphere close-packing by spin coating. Science China Technological Sciences, 59(10), 1573-1580. doi:10.1007/s11431-016-0316-2

Wen, H., Jung, H. ve Li, X. (2015). Drug Delivery Approaches in Addressing Clinical Pharmacology-Related Issues: Opportunities and Challenges. The AAPS Journal, 17(6), 1327-1340. doi:10.1208/s12248-015-9814-9

Xie, Z., Paras, C. B., Weng, H., Punnakitikashem, P., Su, L.-C., Vu, K., ... Nguyen, K. T. (2013). Dual growth factor releasing multi-functional nanofibers for wound healing. Acta Biomaterialia, 9(12), 9351-9359. doi:10.1016/j.actbio.2013.07.030

Yu, D. G., Branford-White, C., White, K., Li, X.-L. ve Zhu, L.-M. (2010). Dissolution Improvement of Electrospun NanofiberBased Solid Dispersions for Acetaminophen. AAPS PharmSciTech, 11(2), 809-817. doi:10.1208/s12249-0109438-4

Yu, M., Huang, J., Zhu, T., Lu, J., Liu, J., Li, X., ... Liu, F. (2020). Liraglutide-loaded PLGA/gelatin electrospun nanofibrous mats promote angiogenesis to accelerate diabetic wound healing via the modulation of miR-29b-3p. Biomaterials Science, 8, 4225-4238.doi: /10.1039/D0BM00442A

Zhang, J., Duan, Y., Wei, D., Wang, L., Wang, H., Gu, Z. ve Kong, D. (2011). Co-electrospun fibrous scaffold-adsorbed DNA for substrate-mediated gene delivery. Journal of Biomedical Materials Research Part A, 96A(1), 212-220. doi:10.1002/jbm.a.32962 